myth and that peer pressure would protect against overspending amongst consultants. According to him, the days of over-spending as a strategic ploy have long since disappeared.

Training issues also arose. It was pleasing to hear that Shell is prepared in principle to undertake to train NHS trainees if the goals are welldefined and the association can prove mutually beneficial; they already have experience of training Civil Service employees and head teachers. One questioner expressed concern about how trainees were to get comprehensive management training when funding is increasingly limited and he raised the question of how doctors should react to unpopular management decisions which they know will make the NHS more difficult to run. Dr Master suggested that there are two responses to this situation: either you do not cooperate and make a fuss, thereby risking an outside auditor being brought in to manage, or you challenge from within the system. He prefers the latter option which he feels allows one to retain control. This sentiment was echoed by Dr Thornley who told us that the unpopular management decision from above is also a problem for personnel in industry. The practical way to deal with this is to demonstrate clearly to top management how services will be affected by new constraints and what problems will arise. It is the role of a manager to challenge, otherwise one ends up as a mere cypher. That challenge may lead to a total re-examination of the whole organisation, which perhaps is not a bad thing.

\title{
Appointments of consultant locums
}

In 1984 the Court of Electors prepared a Memorandum giving advice on locum consultant appointments. This was included in the Handbook of the Joint Committee on Higher Psychiatric Training. However, it did not receive a wider circulation.

Council has recently approved this document with some minor revisions. It emphasises that locum appointments should only be made after careful consideration and for short periods of time. The person must have received appropriate training. A long-term locum consultant appointment is not a substitute for higher training in an approved senior registrar training scheme.

\section{Recommendations}

(1) No doctor should be appointed to a short-term locum consultant post who has not been sufficiently trained to assume all the responsibilities of a consultant. This limits those eligible to:

(a) recently retired consultants

(b) senior registrars within a short time of completion of training for whom only three months locum consultant experience is recognised for the purposes of higher training

(c) fully trained senior registrars or others suitably qualified and experienced, who are not yet ready to commit themselves to a permanent consultant post, or who would never wish to do so

(d) those trained under other comparable systems recognised by the College (e.g. overseas) but whose training has not necessarily been identical in form and content.
(2) The criteria of eligibility for appointment to consultant status produced by the College are respected by employing authorities (with statutory support) and are designed to provide acceptable standards for the safety and care of patients. It would therefore be wrong to waive them for short-term appointments. A statement of these criteria is sent to all College Representatives on Advisory Appointments Committees.

(3) These guidelines should apply to all locum posts. Where it is anticipated that the locum arrangement will last for more than three months a full Advisory Appointments Committee should be convened.

If the locum arrangement has lasted for more than three months an Advisory Appointments Committee should be convened to decide whether the arrangement should continue. Locum arrangements should not normally be continued beyond three months unless there are explicit and defined reasons.

(4) No appointment should be confirmed until the local consultants or their representatives have personally checked the applicant's references with his/her former colleagues. This should be a mandatory provision.

(5) If applicants for short-term locum consultant posts do not meet the conditions under (1) then either:

(a) no appointment should be made

(b) an appointment should be made at a grade appropriate to the needs of the service. If an appointment is made to a training grade, consideration should be given to the educational 
needs and consultant supervision of the trainee.

In no circumstances should a candidate be appointed to a post in which he/she would have to "act up" beyond his/her trained capability. This would at best be inimical to the maintenance of standards and at worst dangerous to patients. Moreover it throws an excessive burden of responsibility upon other medical staff in the same and in associated specialties.

(6) The College will always be prepared to help in a general way from its fund of background knowledge, but is not prepared to hold lists of potential locums with opinions as to their suitability. Advice and confirmation can always be obtained on claims to possess a higher diploma of Membership or Fellowship and on training reached in a higher professional training scheme.

(7) Judgements of the Employment Appeal Tribunal have underlined the importance of careful consideration of locum tenens appointments. Evidence presented to this Tribunal has shown that some locums continue to hold their appointments for many years. On other occasions the appointment may be short and temporary. The Tribunal has pointed out that when a temporary appointment comes to an end it is the duty of the employing body to consider the position of the employee. What will then be appropriate will depend on the circumstances of each case (how long he or she has been employed, what the understanding was when the employee was engaged, what the circumstances are of the employing body and so forth). However, the irreducible minimum requirement is that the employee's position should be considered, and that he/she should not be treated upon the expiry of this short-term contract of employment as though he/she enjoyed no statutory rights at all.

April 1989

\section{French course at CIEP}

\section{Ellis, Consultant Psychiatrist, Child, Adolescent \& Family Service, Dragon Parade Clinic, Harrogate}

The first French Language Course organised by the Royal College of Psychiatrists took place in November 1988 for a week. It was held at Sèvres on the outskirts of Paris in a building of historical interest. The Centre International d'Etudes Pedagogiques was built in 1756 by Louis XV near the Palace of Versailles as a factory for the manufacture of white porcelain and is now a centre for le perfectionnement de la langue française! Groups of about 20 students, usually teachers of French as a foreign language but also administrative and scientific students, make up the $\mathbf{3 0 0}$ or so weekly intake. There were Polish, Hungarian and Norwegian teachers, French geologists and African administrators while we were there.

Professor Robin Priest was the College organiser, and with the directrice, Mme Fenouille, and her staff a stimulating programme of French for psychiatrists and visits to hospitals was put together. The lecturers had worked hard to adapt their course to be highly relevant to ourselves. There was the flavour of a membership viva to the first plenary session when we were given psychiatric terms to define.

The administrative system of the French Health Service became a little clearer as the week progressed, and the similarities and differences in mental health care were highlighted by visits to the hospitals of St Antoine and La Pitié-Salpêtrière. The latter was especially relevant to the three child and adolescent psychiatrists in the group. Professor Michel Basquin and his staff explained the service and the foundation of this famous establishment. French professional hospitality was upheld with a glass of champagne at the end of this visit.

We were steeped in French and French psychiatry for a week and a few of the group visited the theatre to see La Leçon by Ionescu. The course is highly recommended for future years to any psychiatrist with an interest in France and French psychiatry and a basic knowledge of spoken French. 